\title{
Sonora y los sonorenses: el proceso social de la revolución de 1910
}

\author{
M. H. Cynthia Radding
}

\section{Introducción}

a revolución de 1910 , objeto ya de una historiografía a la vez abundante y crítica, capta la atención nacional especialmente durante este año de 1985 que marca el septuagésimo quinto aniversario de sus inicios. A lo largo de los diversos coloquios, encuentros, síntesis, exposiciones y programas radiofónicos y de televisión, se observa un marcado interés por los procesos regionales. En la misma medida en que las investigaciones históricas sobre el devenir contemporáneo de México revelan más y más la diversidad de sus regiones, las indagaciones sobre el pasado definen su objeto de estudio en términos del ámbito regional.

Llaman la atención los origenes de la Revolución en una región como Sonora, cuyos dirigentes lograron dominar el proceso de restructuración del Estado nacional durante la lucha por el poder que fue desatada a partir del Plan de San Luis. Buscamos las explicaciones sobre el proceso regional y sus manifestaciones en la política económica de la facción triunfante del constitucionalismo en el contexto social sonorense de este periodo, cuyo retrato refleja los cambios estructurales producidos en la región durante el porfiriato.

Las consideraciones aquí presentadas siguen las dos etapas principales de las luchas revolucionarias: la maderista y la constitucionalista. Nos preguntamos ¿cómo se vivió la Revolución en Sonora? y ¿cuál fue su impacto social en la región? Al reflexionar sobre el tejido social que dio particularidad histórica a esta región, ofrecemos algunas interpretaciones sobre la combinación de visión política y circunstancias favorables que abrieron al grupo sonorense el camino a la presidencia y a la creación de nuevas instancias de poder.

Retomando los hilos de la historia nacional, podemos afirmar que el movimiento antirreeleccionista al cual Francisco I. Madero había dado su nombre y un programa tomó cauces que él mismo ya no pudo controlar. El llamado a convocar elecciones libres había incendiado la rebelión popular que dio voz a las antiguas demandas campesinas para la restitución de sus tierras comunales y a las reivindicaciones más recientes de los obreros industriales para mejores salarios y condiciones de vida. La movilización de las clases trabajadoras dio al movimiento su contenido revolucionario.

La crisis política de 1913 instigada por la contrarrevolución huertista, sumergió a México en una guerra civil de proporciones masivas que penetró en todas las regiones del país. Su secuela obligó a la renegociación de alianzas políticas entre sectores de estas clases y la nueva burguesía que ocupó el poder. La definición de sus términos adquirió solidez en las estructuras jurídicas de la Constitución de 1917. Las sucesivas etapas y corrientes de la Revolución, contrastantes y a veces contradictorias entre sí, encuentran su explicacion en el medio social 
que las produjo. En este sentido, la base social del villismo de Durango y Chihuahua contrastaba con el universo morelense que dio vida al zapatismo, aun cuando ambos movimientos tuvieron un fuerte contenido campesino. Al interior del constitucionalismo, la perspectiva conservadora de Madero y Carranza, cuyos planteamientos políticos estaban fundamentados en las tradiciones que conservaban todos los hacendados, se enfrentó con la mentalidad empresarial de la burguesia agraria sonorense. El presente artículo explora algunos aspectos de la dirección que tomó la Revolución en Sonora, relacionando las manifestaciones ideológicas y la actuacion politica de los diferentes sectores participantes con las estructuras de esta sociedad regional. ${ }^{1}$

\section{La crisis del régimen cientifico: de la Junta de Notables a la Junta Revolucionaria}

Es lugar común en la historiografía sobre la Revolución hablar de las causas económicas y políticas que amenazaron las estructuras del orden porfiriano al iniciarse el presente siglo. Se cita con mayor frecuencia el cambio del patrón plata al patrón oro con la consecuente baja en el precio de la plata que repercutió en numerosos centros mineros de México a partir de 1905 y la crisis financiera mundial de 1907-1909 que forzó el cierre de industrias y minas por ambos lados de la frontera binacional. Esto tuvo como secuela el regreso de miles de trabajadores mexicanos que habian encontrado empleo en los Estados Unidos y el despido temporal de otros más que laboraban en los enclaves mineros de los estados fronterizos de México. Las pérdidas de cosechas registradas durante los mismos años - aunadas al espectro del desempleo que envolvió a los sectores industriales - precipitaron los levantamientos de las masas trabajadoras que, para la segunda década del siglo, dieron fuerza popular al movimiento antirreeleccionista que desafió los cimientos políticos del régimen de Díaz.

En el ámbito político, el endurecimiento de la oligarquía que se mantuvo en el poder restó validez a las alianzas que Porfirio Díaz había forjado con paciencia y habilidad durante aproximadamente cinco lustros. Se abrieron grietas en la delicada red de concesiones recíprocas que había unido a las clases dominantes de las diversas regiones del país con el aparato centralista del Estado. Factor importante que exacerbó este desequilibrio fueron las concesiones extraordinarias otorgadas por el gobierno central a las empresas extranjeras, principalmente para la construcción de los ferrocarriles, el desarrollo de la minería industrial y el fraccionamiento de tierras comunales para su arrendamiento. Los estados de Baja California, Sonora y Sinaloa, en especial, sufrieron una fuerte penetración de capital extranjero debido a la expansión de los sistemas de irrigación para la agricultura comercial destinada a la exportación. Aquí nos referimos al complejo agrícolaferrocarrilero de Topolobampo, a la expansión de la Sonora \& Sinaloa Irrigation Company y de la Richardson Construction Company en el Valle del Yaqui y a la presencia de la Colorado Land and River Company en el delta del río Colorado.

1 Las interpretaciones aquí expresadas son el resultado de la investigación realizada para la Historia General de Sonora tomo IV (en prensa) sobre el porfirismo y la Revolución en Sonora. La primera versión de este trabajo fue presentada al X Simposio de Historia de Sonora, Hermosillo, Sonora, el 22 de febrero de 1985. 
La capacidad desmesurada de acumulación demostrada por los intereses extranjeros creó motivos de descontento para la burguesía regional que, con el tiempo, se tradujeron en expresiones de rebeldía. La escisión de la clase dominante en Sonora se observa en el hecho de que la Junta de Notables convocada en enero de 1911 por el gobernador Luis E. Torres para exhortar a la defensa del régimen, contaba entre los asistentes con algunas de las familias principales - v.gr. los Maytorena de Guaymas y los Morales de Ures- que desde septiembre del año anterior estaban preparando la insurrección maderista en el estado. La Junta Revolucionaria fundada por Maytorena en Nogales, Arizona, a fines de noviembre de 1910, emitió propaganda y organizó el envío clandestino de armas a los rebeldes que ya se habían movilizado en Sonora.

Estas dimensiones del desenlace porfirista son importantes para explicarnos por qué estalló la Revolución de 1910. Pero no son suficientes para comprender el fenómeno histórico en toda su complejidad. Por ello ampliamos nuestros parámetros al buscar las explicaciones sobre los orígenes de la Revolución en la estructura misma de la sociedad regional que, en muchos sentidos, fue producto del porfirismo.

\section{Las bases sociales para la lucha política}

Nuestra consideración de la sociedad sonorense en vísperas de la $\mathrm{Re}$ volución gira en torno a cuatro vertientes principales:

- la ascendencia de nuevas capas de la burguesía;

- la expresión política de las clases medias;

- el movimiento obrero y

- la lucha ancestral por la tierra.

Las clases sociales que tomaron forma al iniciarse el presente siglo mediante alianzas cambiantes y cierta definición de sus intereses de grupo, no demostraron claras separaciones entre sí, sino que surgieron por etapas a lo largo del siglo XIX. Su desenvolvimiento lento y no siempre lineal es parte del largo periodo formativo de la República. Sus orígenes se remontan hasta las principales instituciones coloniales de la región: la misión que conservaba la comunidad indígena, la hacienda o rancho que consolidó la propiedad privada, el presidio militar cuyos soldados eran a la vez colonos y agricultores y el real de minas al que confluyeron distintos grupos étnicos, dieron forma a la clase trabajadora de Sonora.

La burguesía sonorense, tradicionalmente fincada en las actividades agropecuarias y el comercio, asumió nuevos caracteres precisamente a partir de la expansión económica del porfirismo. El establecimiento de los grandes complejos mineros (Cananea, Nacozari, La Colorada y La Trinidad), así como la modernización de las haciendas agrícolas y las incursiones de las propias familias sonorenses en las industrias de procesamiento de materias primas, abrieron nuevas oportunidades de empleo especializado en ingeniería y en administración. ${ }^{2}$

2 Véase el interesante análisis de Stuart Voss, On the Periphery of Nineteenth-Century Mexico: Sonora and Sinaloa, 1810-1877, Tucson, University of Arizona Press, 1982; "Northwest Mexico", en Diana Balmori, Stuart F. Voss y Miles Wortman, Notable Family Networks in Latin America, Chicago, University of Chicago Press, 1984, p. 79-128. 
La generación de sonorenses que suscribió el movimiento antirreeleccionista provenia generalmente del estrato de la pequeña burguesía. Aun cuando los administradores de molinos harineros y de tenerias y los ingenieros que realizaban los deslindes y diseñaban los sistemas de irrigación no poseyeran los medios de producción, sí recibian los beneficios de las empresas capitalistas que iban en ascenso. En algunos casos los vinculos de parentesco les ligaban con los grandes propietarios del agro sonorense. Ejemplos sobresalientes de lo anterior son Plutarco Elias Calles, quien administró la hacienda de Santa Rosa, propiedad de los Elías en el municipio de Fronteras, y Alvaro Obregón Salido, quien obtuvo sus primeros empleos en la hacienda Tres Hermanos, la próspera finca de sus tíos maternos en el Valle del Mayo. No obstante sus fuertes nexos con los principales propietarios de la entidad, su posición de clase contrastaba con las oligarquías establecidas y se manifestaba, particularmente, en el nacionalismo revolucionario que sería la política central de los constitucionalistas sonorenses.

A estas capas inferiores de la burguesía seguían las de la clase media. Sus ocupaciones eran heterogéneas e incluían a los arrendatarios, pequeños rancheros y agricultores, comerciantes menores al por menor, maestros, algunos artesanos especializados, etc. Estos sectores medios constituyeron una nueva fuerza en la sociedad regional que dominó la lucha por el poder a lo largo de la década revolucionaria. Su posición de clase era antioligárquica, pues predicaba la movilidad social y forjó alianzas con las clases trabajadoras según se requería para construir un consenso político. Los elementos más radicales de la clase media se unieron al movimiento obrero a través del móvil ideológico del Partido Liberal Mexicano.

Los obreros organizados constituyeron el segundo tronco fuerte de la Revolución en el norte. Sus orígenes de clase tienen semillas en la industrialización porfirista. Su participación cada vez más decisiva en la política abrió una nueva dimensión en la lucha por el poder y el forjamiento de nuevas estructuras jurídicas para el país.

Las crisis económicas de 1905-1909 señaladas anteriormente restringieron la capacidad de la economía mexicana para proporcionar empleos al creciente número de obreros. La tasa de crecimiento de la fuerza de trabajo industrial bajó durante el último decenio del porfiriato, mientras que aumentó la población `de peones agrícolas entre 1895 y 1910. La emigración de los trabajadores mexicanos a los Estados Unidos se intensificó a partir de 1900.

Las condiciones de vida y de trabajo que prevalecian aún en las industrias modernas de la minería y las comunicaciones contribuyeron al descontento obrero. El salario real de los obreros de la industria bajó drásticamente durante la última década del porfịriato. La vivienda de los trabajadores mineros distaba mucho de las condiciones dignas a las cuales aspiraba la población urbana. En Nacozari, centro minero de Phelps Dodge en el nororiente de Sonora, los mineros vivían en chozas de una sola pieza que medían aproximadamente cinco metros cuadrados. Para el primer decenio de este siglo, Cananea reportaba serios problemas respecto a la salubridad pública. El contagio de las enfermedades endémicas como la neumonía, la influenza, el paludismo y la tifoidea se atribuía a la contaminación del agua y a la vivienda precaria, condiciones características de El Ronquillo, el barrio obrero del mineral.

La discriminación contra los trabajadores mexicanos en el empleo y 
la inferioridad de salarios era notoria, sobre todo en los ferrocarriles y las industrias mineras de capital extranjero. Fue el factor principal que encendió la huelga de 1906 en Cananea y sus repercusiones intensificaron el nacionalismo expresado por los ferrocarrileros mexicanos. ${ }^{3}$

¿Quiénes engrosaron las filas de las clases trabajadoras en la víspera de la Revolución? Los trabajadores del campo sonorense incluían a los aparceros, a los pequeños labradores que arrendaban las milpas de cultivo o pagaban los derechos de pastoreo en las haciendas y ranchos de la zona serrana; a las comunidades indigenas del Yaqui y del Mayo y a los trabajadores libres inmigrados a los valles costeros. Los pobladores que fueron conformando la masa de obreros industriales en los centros principales como Cananea, Nacozari y La Colorada tenían orígenes diversos. Llegaron a los minerales tanto los jornaleros del campo como la mano de obra especializada que provenía de otras zonas mineras. Asimismo, los campesinos de la región trabajaban en las minas por temporadas durante los periodos de descanso en el ciclo agrícola. Los grupos indigenas, especialmente los yaquis, fueron siempre un elemento importante en la fuerza de trabajo industrial. Se empleaban en el tendido de las vías férreas, los campos mineros y las faenas agrícolas.

Los obreros mineros ubicaron su principal zona de trabajo en el noroeste de Sonora y el sur de Arizona. Los grandes minerales cupríferos de Cananea y Nacozari tuvieron su contraparte en Bisbee, Globe y Clifton Morenci, al norte de la frontera. Las incipientes organizaciones proletarias se alentaron con las experiencias comunes vividas en los centros mineros de ambos países. Pese a la legislación porfirista que prohibía la formación de sindicatos en Sonora, los nexos entre los trabajadores industriales de Arizona y Sonora proliferaron por intermedio de los clubes y focos del Partido Liberal Mexicano. Se comunicaron por conducto de visitas directas, correspondencia y divulgación de los programas del partido en sus periódicos. Su ideología se vio influida por la Western Federation of Miners y la Industrial Workers of the World. Si bien el PLM dio a los trabajadores de esta región su primera estructura política, los obreros industriales contribuyeron a la formación de los primeros núcleos del Partido Antirreeleccionista en apoyo a la candidatura de Madero. Los líderes obreros sonorenses que primero habían seguido los lineamientos magonistas, participaron en la insurrección maderista de 1911 que terminaria con el régimen de Porfirio Díaz. $^{4}$

La resistencia campesina contra el despojo de sus tierras, constituye en Sonora la lucha ancestral de los yaquis. Su participación en la Revolución es contradictoria. Mientras que algunas bandas de guerrilleros mantuvieron viva la defensa de sus tierras y pueblos, otros yaquis ingresaron a las tropas federales y los ejércitos formados por los maderistas y constitucionalistas de Sonora. Los yaquis son sujetos de su propia historia en cuanto a su tenaz lucha de reivindicación comunera. No

${ }^{3}$ Barry Carr, El movimiento y la política en México, 1910-1929, México, Sep Setentas, 256-257, 1976, vol. I, p. 16, 20; Eugenia Meyer, (Coordinadora), La lucha obrera en Cananea, 1906, México, Secretaría de Trabajo, 1980, p. 30-38; Ramón Eduardo Ruíz, La revolución mexicana y el movimiento obrero. 191/-1923. México, Ediciones Era, 1978, p. 62-64.

${ }^{4}$ Véase Carr, 1976; Ruíz op cil., 1978; Dirk W. Raat, Revoltosos. Mexico's Rebels in the United States, 1903-1923, Texas A \& M University Press, 1981; Ismael Valencia Ortega, "Desenvolvimiento de la clase obrera en Cananea (1900-1932)", VIII Simposio de Historia de Sonora, Hermosillo, Universidad de Sonora, 1984. 
obstante lo anterior, no hicieron suyos los principios politicos del levantamiento de 1910. En cambio, su causa fue aprovechada -y después mediatizada- por los revolucionarios sonorenses en su oposición a las oligarquías establecidas.

\section{Una sociedad en guerra}

Las entrevistas de historia oral, principalmente, permiten captar las vivencias de los años de la Revolución en los poblados rurales de Sonora. Las memorias de hombres y mujeres, entonces niños o adolescentes, apuntan las experiencias y expresan la incertidumbre de la población civil que permaneció en sus pueblos mientras que los ejércitos sonorenses participaban en los combates decisivos contra el huertismo y el villismo en el centro de la República.

La memoria pueblerina de los años de guerra confirma el principio de autodefensa que había caracterizado al maderismo en Sonora. Las pocas referencias a acciones de armas encontradas en los archivos municipales aluden siempre a la defensa de las familias, casas, tierras y ganado contra las bandas de soldados percibidas como foráneas. Las incursiones de orozquistas y villistas dejaron su huella en los municipios del río Sonora y en los distritos de Sahuaripa y Alamos. Una madre de familia de Alamos que trabajaba de lavandera recordó la ocupación de esta ciudad por fuerzas villistas: el ejército tomaba libremente las mercancias de las tiendas mientras la gente permanecía tras sus puertas; unos soldados llegaron a su casa y le ordenaron que les lavara y remendara los uniformes. Ella, en ese tiempo una niña, fue temblorosa a buscar aguja e hilo. ${ }^{5}$

¿Tuvieron las mujeres un papel especifico en la Revolución? Aunque carecemos de investigaciones analíticas sobre su participación, podemos hacer algunas inferencias. Sabemos que en las plazas fronterizas de Naco, Agua Prieta y Nogales, donde los constitucionalistas se establecieron desde el inicio de la revuelta antihuertista, las mujeres preparaban y distribuían alimentos y, en ocasiones, ayudaban a pasar armas y municiones por la frontera. Aunque no tenemos evidencias claras de la participación de mujeres en los combates, es de suponerse que, en los pueblos, al marchar los hombres a la guerra, sus madres, hermanas y esposas tomaron a su cargo las siembras en las milpas y, con ello, continuaron manteniendo la familia.

Aunque las autoridades estatales se cuidaron de mantener en producción las principales unidades mineras, agrícolas y ganaderas aún durante los años álgidos de la lucha armada, mediante la "intervención" de propiedades y negocios, la carestía afectó los poblados rurales, los centros mineros y las ciudades de Sonora. La producción agropecuaria, ya sea en manos de los propietarios, ya sea por medio de la Oficina de Administración de Bienes Ausentes, fue destinada a la exportación con el objeto de financiar el aparato militar constitucionalista. El alza en los costos de productos básicos fue motivo de manifestaciones y paros obreros en Cananea, Nacozari y La Colorada. Asimismo, eran frecuentes las protestas sobre la carencia de alimentos comunicadas al gobierno del estado por los ayuntamientos. Sus infor-

s PHO/5/11. Entrevista a María Esperanza Sánchez V. de Valenzuela, Alamos, Sonora, 1975, INAH, Centro Regional del Noroeste. 
mes denuncian el abandono de haciendas, el cierre de molinos harineros y la proliferación del abigeato, síntomas éstos de la huella de guerra en la región. ${ }^{6}$

En esta década turbulenta ciertos acontecimientos naturales tienen un enorme impacto local. El año de 1914 trajo lluvias excepcionales, causando inundaciones a diversas zonas del estado. En el extremo sur, el Río Mayo rebasó sus riberas para amenazar el nuevo asentamiento de Navojoa; el año siguiente, el pueblo de Huatabampo sufrió cuantiosos daños debido a las inundaciones. En el municipio de Arizpe, los campesinos de Bamori recuerdan 1914 como el año en que la creciente del río Sonora destruyó las milpas y el poblado entero: sus habitantes se vieron forzados a refugiarse en una cueva durante varios meses, mientras que los jefes de familia construian nuevas casas. ${ }^{7}$

Estos acontecimientos suelen pasar desapercibidos para las historias clásicas que sólo rememoran los eventos políticos y militares. Al comparar distintos contextos históricos, pero contemporáneos entre sí, reflexionamos y vemos que en Europa, 1914 fue el inicio de la primera guerra mundial; en Zacatecas, la División del Norte derrotó al ejército federal, obligando a la inmediata destitución de Huerta; en Naco, los maytorenistas y los callistas pugnaron por el control regional. Pero en Bamori, 1914 fue el año de la creciente, el año de la cueva.

\section{La población: salud, carestía y migraciones}

Los indicadores demográficos nos ayudan a interpretar el contexto social en Sonora durante la Revolución. Nos proporcionan las bases para medir el impacto relativo de la guerra en Sonora, comparado con otros estados de la República. El incremento o decremento de la población durante el periodo revolucionario nos muestra, en parte, la capacidad de la economía regional para superar las crisis generadas por un estado de guerra civil y recuperar o aumentar sus niveles de producción. (Desde luego que los informes demográficos no son más que indicadores; no nos explican cómo se distribuye la producción ni cuáles son los patrones de acumulación que predominan en las sociedades estudiadas.)

Las interpretaciones de los censos nacionales de 1910 y 1921 expresadas en la literatura clásica sobre la Revolución señalan una baja drástica en la población global, como se aprecia en el cuadro 1, que compara los censos mexicanos de 1895 a 1960.

Estudios recientes han cuestionado la supuesta "pérdida" de 825589 habitantes, atribuyendo la discrepancia entre los censos de 1910 y 1921 a irregularidades en los procedimientos de conteo, señalando un marcado subregistro en el año de $1921 .^{8}$ Sus conclusiones toman en consideración el subregistro crónico de los nacimientos, el impacto de las

"Susan M. Deeds, "José Ma. Maytorena and the Revolution in Sonora", Part. II, Arizona and the West, vol. 18, núm. 2, 1976, p. 141; Archivo del Boletín Oficial del Estado de Sonora (ABOS), tomo IV, 33, p. 2-3; Archivo Histórico del Gobierno del Estado de Sonora (AHGES), Hacienda 3147, 3148, 3200.

7 Socorro Gallareta Partida, "Las aguas del Río Mayo, (1900-1920)", VIII Simposio de Historia de Sonora, Hermosillo, Universidad de Sonora, 1984, p. 399-499; información de la Maestra María Elena Montijo y los alumnos de la Escuela Primaria 20 de noviembre de Bamori, Sonora.

- Véase Robert G. Greer, Demographic Impact of the Mexican Revolution 1910-1921 (Tesis de maestria), University of Texas at Austin, 1966. 
migraciones y las dificultades administrativas para organizar de nuevo el Departamento de la Estadística Nacional después de la década militar de la Revolución. ${ }^{9}$

El problema del subregistro para el censo de 1921 es ejemplificado por Sonora. La cifra estatal reportada en 1922 fue de 270759 habitantes; sin embargo, los resultados publicados en 1928 indicaron 275127 sonorenses en el año de 1921. La diferencia se debió a que en la primera

\section{Cuadro 1}

\begin{tabular}{|l|l|}
\hline \multicolumn{2}{|c|}{ Censos nacionales de México } \\
\hline Año & Población \\
\hline 1895 & 12632427 \\
1900 & 13607259 \\
1910 & 15160369 \\
1921 & 14334780 \\
1930 & 16552722 \\
1940 & 19653552 \\
1950 & 25791017 \\
1960 & 34923129 \\
\hline
\end{tabular}

Fuente: Anuario Estadístico de los Estados Unidos Mexicanos, 1965.

\section{Cuadro 2}

\begin{tabular}{|l|r|r|r|r|}
\hline \multicolumn{5}{c|}{ Movimientos demográficos: 1910-1921 } \\
\hline & \multicolumn{1}{|c|}{1910} & 1920 & Incremento & Decrecimiento \\
\hline Estado & & & & \\
\hline Sonora & 265383 & 275127 & 9744 & \\
Sinaloa & 323642 & 341265 & 17623 & \\
Baja California & 52272 & 62831 & 10559 & \\
Chihuahua & 405707 & 401622 & & 4085 \\
Coahuila & 362092 & 393480 & 31389 & \\
Durango & 483175 & 336766 & & 146409 \\
Guanjuato & 1081651 & 860364 & & 221287 \\
Jalisco & 1208855 & 1191957 & & 16898 \\
Morelos & 179594 & 103440 & & 76154 \\
Zacatecas & 477556 & 379329 & & 98227 \\
Yucatán & 339613 & 358221 & 18608 & \\
\hline
\end{tabular}

Fuente: Estados Unidos Mexicanos. Departamento de Estadistica Nacional. Resumen Ge. neral del Censo General de Habitantes (1928) citado en Greer, 1966, p. 6.

- El citado departamento fue fundado durante la presidencia de Alvaro Obregón en 1922 bajo la dirección de Manuel Padrés y, a su muerte en 1926, el departamento se quedó a cargo de Juan de Dios Bojórquez, destacado sonorense que sistematizó y amplió las compilaciones estadísticas y los procedimientos censales en México. Durante su administración, Bojórquez publicó Sonora, Sinaloa, Nayarit, estudio estadístico económico social elaborado por el Departamento de Estadística Nacional (México, 1928). 
compilación, los municipios de Tórim y Pótam no fueron tomados en cuenta. ${ }^{10}$ Recordemos que se trataba de pueblos tradicionalmente poblados por yaquis que para esas fechas aún disputaban sus tierras a los colonos yoris que las habian ocupado.

Tomando en cuenta las irregularidades en el referido censo, es interesante comparar el comportamiento de la población sonorense con el de otros estados. El cuadro 2 muestra las cifras correspondientes a los censos de 1910 y 1921 para algunos estados seleccionados según su distinta participación en la Revolución.

Observamos en el cuadro anterior que durante la década revolucionaria se acentuaron algunas tendencias observadas tradicionalmente en el movimiento de la población. En los estados de la frontera norte, con excepción de Chihuahua, así como en la península de Yucatán, se aumentó el número de habitantes. Sonora experimentó un aumento ligero de $3.6 \%$ en su población. El incremento es más notable en el caso de Baja California. Si recordamos que el gobierno inició un programa de colonización del delta del río Colorado en 1917, podemos aseverar que el fenómeno demográfico se debió más a la inmigración que al incremento natural de la población.

En contraste, el Bajío, el sur zapatista y la antigua zona minera colonial de Zacatecas y Durango sufrieron bajas demográficas. Las causas pueden ser variadas: la guerrilla villista y zapatista y su represión por las fuerzas carrancistas que provocaron bajas militares y civiles y la destrucción de milpas y campos de cultivo; las carestías ocasionadas por la baja producción de alimentos y los obstáculos para su distribución; la extensión de epidemias y las migraciones de una región a otra o hacia el extranjero. Este último factor fue importante para los estados fronterizos, entre ellos Sonora, pues constituyeron una región receptora de pobladores que pretendían buscar trabajo allí mismo o pasar a los Estados Unidos.

A pesar del saldo demográfico favorable para Sonora, nuestro estado no dejó de sentir los efectos de las enfermedades contagiosas que, en algunos casos, alcanzaron proporciones epidémicas. Los informes municipales enviados al gobierno del estado durante la década revolucionaria y los años veinte indican brotes repetidos de epidemias y la presencia endémica de las siguientes enfermedades:

El tifo, la tifoidea, la viruela y el sarampión eran algunas de las enfermedades más temidas desde que las epidemias del periodo colonial, tras haberlas propagado los europeos, diezmaron la población indigena. En el periodo aquí bajo estudio parece que la viruela negra fue el mal más severo que con frecuencia incidió en los poblados sonorenses. Repetidamente las autoridades municipales se dirigian al gobierno del estado para solicitar envios de la linfa vacunal con la cual se esperaba proteger a los vecinos, ya porque hubo casos en sus comarcas o ya porque tenian noticias de los brotes de la viruela en los municipios circundantes. ${ }^{10}$

La influenza española, pandemia de proporciones grotescas en varios continentes, pasó de los Estados Unidos a México en 1918. Su contagio afectó a casi todas las regiones del pais, pues su penetración geográfica fue exacerbada por el movimiento de tropas entre Europa y las

10 Greer, op. cit., p. 47-48.

" AHGES Salubridad 3256. 
Cuadro 3

\section{Enfermedades más comúnmente registradas en el estado de Sonora} 1918-1922

\begin{tabular}{|l|l|l|}
\hline & Sarampión & Tosferina \\
Difteria & Sífilis & Tracoma \\
Fiebre amarilla & Tifo & Tuberculosis \\
Paludismo & Tifoidea & Viruela \\
& & \\
\hline
\end{tabular}

Fuente: Archivo Histórico del Gobierno del Estado de Sonora 3471, 3500.

Américas debido a la Primera Guerra Mundial y, en México, por las luchas revolucionarias. La epidemia causó alarma en Sonora, primero en 1918 y de nuevo en 1920, aunque el primer año fue el más crítico. Su presencia se manifestó en los centros mineros del sur de Arizona - Ajo, Bisbee, Warren, Globe y Douglas - en la primavera de 1918 y la epidemia se declaró en toda su plenitud, tanto en el norte como en el sur de Sonora, en diciembre de ese año. Las autoridades tomaron medidas preventivas para el aseo de las casas y las calles, el cierre de las escuelas y centros de reunión y la cuarentena de personas en tránsito de los Estados Unidos o poblados de la propia entidad donde ya se habían reportado casos de esta influenza mortal.

Aunque los informes municipales no dan cifras exactas sobre el número de casos y fatalidades, sus observaciones son pertinentes para interpretar el impacto social de la epidemia. En primer lugar, sobresale el hecho de que la gran mayoría de las víctimas eran de los estratos más pobres de la población, quienes no podían alimentarse adecuadamente ni comprar las medicinas para curarse; segundo, los municipios no contaban ni con instalaciones ni con medicamentos para combatir la enfermedad y, en general, el estado dependía de los Estados Unidos para el suministro de las vacunas y medicinas y, tercero, Sonora carecía de médicos para atender a la población. Llama la atención que, sobre todo en los poblados fronterizos, los médicos que socorrían a los enfermos eran de origen extranjero o vivían en las ciudades del sur de Arizona. Los estragos de la epidemia de influenza española hicieron más evidente la miseria, producto del hambre y del desempleo, que subsistía en Sonora, aun cuando éste fuera considerado entre los estados más prósperos de la República. ${ }^{12}$

\section{El entorno social y el curso de la Revolución en Sonora}

Merece subrayarse que no se trata de la Revolución de 1910, sino de varios movimientos de rebelión social y política que confluyeron en una red compleja y a veces contradictoria de actores y corrientes ideológicas.

Los dirigentes, de origen terrateniente, burgués y clase media, formaron la nueva capa de la burguesía sonorense que tomó el poder en el estado y llevó su programa a los niveles nacionales. Durante la etapa mi- 
litar, los revolucionarios sonorenses de bandera maderista y constitucionalista presentaron fisuras y divisiones entre sí, aun cuando el desconocimiento de Huerta por el Congreso del Estado se expresara como una declaración unida. Sus conflictos se explican por las diferencias en su origen de clase y en su postura política. La burguesía regional ostentaba una ideología empresarial, engendrada en el liberalismo clásico, pero influida fuertemente por la expansión del oeste norteamericano y la penetración de capital estadunidense en la región. Sus valores contrastaban con el conservadurismo de los campesinos indigenas que lucharon durante todo el periodo por preservar sus comunidades.

Vista desde esta perspectiva, la política de gobierno y el contenido reformista que los dirigentes sonorenses dieron al programa social de la Revolución se explican, en parte, por su posición de clase. Los líderes conscientes de conformar una nueva elite empresarial en ascenso buscaron ciertas alianzas con las incipientes organizaciones obreras y crearon instituciones de gobierno que permitieron al Estado encauzar los movimientos laborales para sus fines. En contraste, su política agraria favoreció siempre la pequeña propiedad privada, aun manteniendo intactas algunas haciendas de considerable extensión, sobre los reclamos de restitución o dotación de las posesiones comunales. En Sonora, mientras que el movimiento obrero logró ciertos avances durante la misma década revolucionaria, la reforma agraria fue pospuesta prácticamente hasta la etapa cardenista, con algunas excepciones importantes entre las cuales se destaca la expropiación de la Compañia Richardson en 1926, durante la presidencia de Plutarco Elías Calles. ${ }^{13}$

Las masas hicieron sentir su presencia a lo largo del proceso revolucionario en los ejércitos del noroeste, reclutados en gran medida en los campos mineros de la sierra sonorense. Su voz se escucha en las mismas organizaciones obreras que comenzaron a tomar forma y dar expresión a las demandas laborales y en la lucha comunera particular de los yaquis. En general, la voz obrera cobró mayor peso durante este periodo. Tras las movilizaciones revolucionarias el sindicalismo industrial en Sonora alcanzó nuevos niveles de madurez. En contraste, la voz comunera fué débil y mantuvo su carácter étnico de especificidad en torno a la demanda de tierras para las comunidades indígenas del Valle del Yaqui. Los campesinos sonorenses incluyeron a los milperos, aparceros y jornaleros del campo. Como hemos visto, el reparto agrario fue postergado en Sonora debido a que los dirigentes de la región siempre dieron preferencia a la vía de la pequeña propiedad y los mismos campesinos formularon sus demandas sociales en términos de sus condiciones de trabajo. En esta primera instancia, sus exigencias no recayeron sobre las tierras en sí.

\section{¿Por qué triunfó el "grupo sonorense"?}

A esta pregunta comúnmente escuchada en torno a los eventos de la Revolución de 1910 y la década posrevolucionaria, se plantean algunas explicaciones fundamentales en el origen de clase de esta capa de la burguesía progresista de Sonora. El grupo dirigente que tomó poder en

\footnotetext{
13 Véase Cynthia Radding, "Revolucionarios y reformistas sonorenses: las vias tendientes a la acumulación de capital en Sonora, 1913-1919”. Congreso sobre la Revolución en las regiones, Guadalajara, 1984 y Héctor Aguilar Camin, Saldos de la Revolución, cultura y política de México, 1910-1980, México, Nueva Imagen, 1982.
} 
el estado a partir de 1915 tuvo la capacidad política y contó con las condiciones materiales para llevar a la práctica su programa de gobierno. El éxito de su proyecto se debe a tres factores importantes:

1. La facción sonorense del constitucionalismo formuló un programa de restructuración del Estado nacional. Sus objetivos eran básicamente enfocar la economía hacia el modelo capitalista y construir un nuevo consenso político. Para lograr estos fines, los dirigentes sonorenses forjaron alianzas con ciertos sectores de las clases trabajadoras a la vez que fortalecieron sus relaciones con el capital nacional y extranjero.

2. Durante el periodo revolucionario se conservó el aparato productivo del estado. La etapa de las guerras civiles se concluyó en Sonora en 1915, con lo cual su economía no sufrió las crisis tan severas que caracterizaron a Chihuahua, el Bajío y la zona zapatista de Morelos y Guerrero. Esa "guerra administrada" desde la gubernatura mantuvo intactas las unidades agropecuarias y negoció con las empresas mineras para minimizar los estragos de los paros e interrupciones en su producción. Asimismo, en la década subsecuente, la rebelión cristera no flageló las tierras sonorenses y las revueltas político-militares delahuertista y gómez-serranista no hicieron eco en la región. Aun la escobarista, conocida en Sonora como la Renovadora, de corta duración, no repercutió en la economía regional.

No obstante lo anterior, como observamos en la sección sobre demografía, la población sonorense sí sufrió los efectos de la guerra. Los periodos de desempleo, los obstáculos para distribuir los víveres y las epidemias señaladas imprimieron su huella en la sociedad sonorense. Aun tomando en cuenta estos factores, Sonora se compara favorablemente con otras regiones de la República en cuanto a la preservación de su capacidad productiva.

3. Desde el triunfo del maderismo en Sonora, los gobernantes de la región trabajaron sistemáticamente para lograr la profesionalización de su ejército. Tras la defensa de su territorio contra las incursiones orozquistas y la lucha estratégica contra las fuerzas federales huertistas, el Cuerpo del Ejército del Noroeste alcanzó niveles importantes de organización y movilización. Los métodos de disciplina, financiamiento y equipamiento de las fuerzas armadas sonorenses reflejaron el programa político y los objetivos económicos que guiaron al grupo sonorense.

Con el triunfo sonorense culmina, en muchos aspectos, el ascenso de las clases medias en México. Su programa de gobierno renovó la burguesia que, como clase, dirigió el proyecto político del Mexico posrevolucionario. Los sonorenses que participaron en las contiendas militares, que marcharon en las filas sindicalistas y abrieron nuevas tierras en los valles del Colorado, Yaqui y Mayo ascendieron en número a miles de hombres y mujeres. Son estos trabajadores junto con los del resto del país quienes escribieron un nuevo capitulo en su historia. A ellos pertenece la Revolución. 